\title{
Percepção do visitante sobre a relação entre turismo e meio ambiente no município de Campos do Jordão (SP)
}

\author{
Visitor's perception about the relationship between tourism and environment in \\ the city of Campos do Jordão (SP, Brazil)
}

\section{Sara Ruiz Hirata, Odaléia Telles Marcondes Machado Queiroz}

\section{RESUMO}

Diante da emergência da temática ambiental e considerando sua relevância e repercussão na sociedade, nota-se a importância de estudar a relação entre o homem e a natureza. Nesse sentido, observa-se que a atividade turística, geralmente, é construída por essa interação e quando assim acontece é dependente dos recursos naturais dos núcleos receptores para sua existência e desenvolvimento. Apesar de ser visto como uma alternativa atraente em termos econômicos, o turismo é questionado em relação aos possíveis efeitos indesejáveis no que tange aos aspectos sociais e ambientais. Ciente disso, este artigo aborda o setor em Campos do Jordão, município do estado de São Paulo que recebe intenso fluxo turístico, principalmente nos meses de inverno devido as suas características de relevo e clima. Em uma análise preliminar, é apresentada uma visão do turismo em Campos do Jordão sob a ótica de turistas entrevistados pelos alunos do curso de bacharelado de Gestão Ambiental da Universidade de São Paulo durante prática orientada no local. As informações obtidas viabilizaram a elaboração de uma análise prévia sobre o perfil do visitante e o segmento de turismo local, destacando a ótica deste sobre a geração de impactos socioambientais e o entendimento sobre o espaço visitado e sua característica natural entre outras coisas como Parque Estadual de Campos do Jordão. Os resultados indicaram, entre outros fatores, que os impactos socioambientais são notados superficialmente pela maioria dos visitantes, demonstrando que os efeitos percebidos relacionam-se, quase exclusivamente, à geração de lixo e esgoto. Os efeitos do turismo sobre o agravamento da desigualdade social, sobre os recursos hídricos e florestais são bem pouco observados e denotam o baixo envolvimento dos visitantes com a realidade local do município quanto aos fatores socioeconômicos e ambientais da comunidade local. Este fato pode indicar a carência de instrumentos públicos e privados que estimulem uma relação mais próxima da realidade jordanense e incrementem o turismo na região considerando outras áreas dos meios urbano e rural com potencial turístico, incluindose a sociedade local que poderia ser favorecida com a expansão e planejamento da visitação.

PALAVRAS-CHAVE: Turismo; Ambiente; Campos do Jordão; Percepção. 
Percepção do visitante sobre a relação entre turismo e meio ambiente no município de Campos do Jordão (SP)

\section{ABSTRACT}

Faced with the emergence of environmental issues and considering their relevance and impact on society, notes the importance of studying the relationship between man and nature. In this sense, it is noted that tourism is usually built by this interaction and when this happens is dependent on natural resources of the receiving centers for its existence and development. Despite being seen as an attractive alternative in economic terms, tourism is questioned about the possible side effects with regard to social and environmental aspects. Aware of this, this paper discusses the sector in Campos do Jordão, municipality of São Paulo, which receives heavy influx of tourists, especially during the winter months due to its topography and climate characteristics. In a preliminary analysis, provides an overview of tourism in Campos do Jordão from the perspective of tourists interviewed by the students of Bachelor of Environmental Management, University of São Paulo, during guided practice on site. The information obtained enabled the preparation of a preliminary analysis on the profile of the visitor and the local tourism sector, with emphasis on the perspective of this generation and understanding of social and environmental impacts on the area visited and their natural feature among other things like Parque Estadual de Campos do Jordão. The results indicated, among other factors, social and environmental impacts are noted on the surface for most visitors, demonstrating that the perceived effects relate almost exclusively to the generation of waste and sewage. The effects of tourism on the worsening social inequality, on forest and water resources are very little observed and denote the low involvement of visitors to the actual location of the municipality regarding the socioeconomic and environmental factors of the local population, which may indicate a lack of public and private instruments to encourage a closer relationship to Campos do Jordão reality and foster the tourism in the region considering other areas of urban and rural areas with tourism potential and likely to include members of society who would be favored by the expansion and planning of visitation.

KEYWORDS: Tourism, Environment, Campos do Jordão, Perception.

\section{Introdução}

Atualmente a temática ambiental está presente em praticamente todos os espaços de discussão e de ação da sociedade, tendo um papel importante na construção da identidade humana, especialmente a partir das últimas décadas.

Diante da emergência de uma questão transversal a respeito dos recursos naturais e interações entre o homem e a natureza, é incorporada a temática do turismo e o desenvolvimento de suas atividades, as quais têm no ambiente seu elemento fundamental, tornando evidente a pertinência de se estudar e trabalhar os impactos da visitação sobre o espaço natural. 
Os efeitos da atividade turística sobre o meio ambiente são estudados por alguns autores que discutem as relações estabelecidas entre os turistas e as localidades visitadas, apontando a questão da percepção ambiental e da construção desta com influências dos contextos culturais para o entendimento das interações e proposição de idéias e alternativas que se orientem ao encontro de uma realidade ambientalmente mais amigável.

Essa análise apóia-se nas informações obtidas pelas entrevistas aplicadas pelos alunos do curso de Gestão Ambiental do campus Escola Superior de Agricultura "Luiz de Queiroz", da Universidade de São Paulo, localizado em Piracicaba, conforme explicado melhor no desenvolvimento deste artigo.

Os Parques Estaduais são unidades de conservação de proteção integral, admitindo o uso público legitimado pelo Sistema Nacional de Unidades de Conservação (2000). A presença humana é caracterizada basicamente pelas atividades de pesquisa, recreação e educação ambiental que formam a gama de visitantes que os parques recebem, enquadrando nestes segmentos o turismo.

No cenário de turismo de inverno consolidado em Campos do Jordão, está inserido o PECJ, parque estadual mais antigo de São Paulo, destino de milhares de visitantes todos os anos.

O objetivo principal do artigo é discutir as atividades turísticas em Campos do Jordão considerando a percepção ambiental e motivação dos turistas, destacando a sua interação com o PECJ no período de 2007 a 2011, baseando-se em dados obtidos em prática orientada realizada por alunos do curso de Gestão Ambiental da ESALQ/USP.

Neste sentido, é de interesse deste trabalho apontar o perfil e a percepção dos turistas de Campos do Jordão-SP sobre os impactos ambientais gerados pela visitação no município por meio das entrevistas realizadas entre 2007 e 2011 e levantar considerações pertinentes sobre a noção de conhecimento do Parque Estadual de Campos do Jordão pelos turistas e qual seu grau de atratividade.

O turismo tem múltiplas relações com a sociedade, a economia, a cultura e a natureza, por isso seus aspectos e resultados devem ser considerados para se alcançar uma visão mais ampla e organizada no intuito de gerar subsídios para a tomada de decisão mais consciente e pertinente em cada localidade (RUSCHMANN, 1997).

O município paulista de Campos do Jordão é um dos principais destinos turísticos do Brasil, recebendo cerca de três milhões de visitantes por ano (ARAUJO, 2008). Assim, é um espaço suscetível aos impactos gerados pelo turismo, o que nos faz concordar com Queiroz (2000,p.4) quando diz: "o que se tem visto na maior parte das áreas onde são praticadas atividades de lazer e de turismo é a quase total despreocupação em manter a integridade do ecossistema envolvente" e, em Campos do Jordão não é diferente.

Dessa forma, discutir o turismo que ocorre no município partindo do ponto de 
Percepção do visitante sobre a relação entre turismo e meio ambiente no município de Campos do Jordão (SP)

vista dos turistas, principalmente no que se refere ao PECJ, detectando as suas consequências é uma tarefa importante, pois as informações obtidas poderão servir como subsídio para minimizar alterações, justificando-se a elaboração deste estudo. Ressalta-se também que, para áreas de risco como em Campos do Jordão, a degradação dos recursos naturais pode significar uma redução das oportunidades de recreação e lazer, afastando os turistas.

Para Pacheco e Silva (2007), a percepção ambiental é, atualmente, uma temática recorrente que colabora para a consciência e prática de ações individuais e coletivas. Assim, o estudo da percepção ambiental é relevante para a compreensão das inter-relações entre o homem e o ambiente, suas expectativas, suas satisfações e insatisfações, expectativas, julgamentos e condutas.

Nos estudos sobre percepção ambiental, Garnica (1997 apud CUNHA; LEITE, 2009) diz que a pesquisa qualitativa, ao investigar os fenômenos dando a eles possibilidades de se mostrar, faz com que sua compreensão fique mais clara na medida em que o detalhamento de suas análises é maior, com a interação do pesquisador e o pesquisado, já que o primeiro deve se ver e ver o seu entorno como um grande leque de possibilidades, não somente objetividades e manifestações concretas acabadas, ignorando o processo de construção sociocultural, a situação atual e as expectativas de futuro das comunidades abordadas e pesquisadas.

Cunha e Leite (2009) enfatizam que há vários conceitos para o termo "percepção ambiental", porém é preciso observar que o aspecto essencial é o da questão das relações entre o homem e o meio ambiente, como cada indivíduo o percebe, o quanto conhece do seu próprio meio, o que espera dele, como o utiliza e sua ação cultural sobre esse meio:

... a natureza é aquilo que observamos pela percepção obtida através dos sentidos. Nessa percepção sensível, estamos cônscios de algo que não é pensamento e que é contido em si mesmo com relação ao pensamento. Essa propriedade de ser auto-contido com relação ao pensamento está na base da ciência natural... cujas relações mútuas prescindem da expressão do fato e do que se pensa acerca das mesmas (WHITEHEAD, 1994, p. 09 apud CUNHA; LEITE, 2009).

Quando são consideradas áreas que sofrem influências expressivas, como é o caso de Campos do Jordão em relação ao turismo, a percepção ambiental é notadamente importante de ser estudada, pois pode oferecer informações importantes que servirão de subsídios às futuras intervenções.

Ao mesmo tempo o levantamento da percepção com os atores envolvidos em determinada realidade ambiental, legitima o estudo de avaliação e os futuros projetos de intervenção de uma determinada realida- 
de; busca elucidar as relações de causa e efeito, com a finalidade de subsidiar a escolha de soluções para os projetos; é também uma poderosa ferramenta de trabalho, facilita a avaliação de processos sociais, no interesse de constatar a situação atual dos problemas presentes no meio ambiente, de modo a enriquecer o processo decisório." (LEITE, 2009 apud CUNHA; LEITE, 2009)

Segundo Diaz (2002), a relação da nossa espécie com o meio ambiente, produto da percepção que tem dele, sobretudo de si mesma, sofreu uma revolução interessante e relativamente pouco estudada. Complementando essa afirmação, Cunha e Leite (2009) ressaltam que a visão humana de mundo, do ambiente físico, natural e construído socialmente são diferentes em relação à cultura, às experiências perceptivas, os conceitos e valores incutidos, o que traz como consequências as atitudes que tomamos perante a realidade que nos cerca.

\section{Desenvolvimento}

\section{Turismo e meio ambiente: uma breve contextualização}

O paradigma da sustentabilidade levantou em muitos setores os questionamentos sobre as ações humanas e seus efeitos sobre a natureza. Na área do turismo, isso também ocorreu e tem crescido, existindo assim vários autores que abordam a temática, como Irving (2001) que aponta os desafios para elaboração de uma política de turismo promotora da sustentabilidade ambiental.

Assim como outras atividades econômicas, o turismo pode ter ação destrutiva sobre o ambiente, atingindo a cultura local, muitas vezes negligenciado-a; também pode ocorrer a apropriação de terras para a criação de parques e outras unidades de conservação bem como de construções de complexos hoteleiros e de segunda residência associados a riscos e injustiças sociais.

Pensando no benefício do desenvolvimento local, ressalta-se que é frequente não haver um aproveitamento pelas comunidades receptoras, pois as ações não são efetivamente comprometidas como um todo e com o desenvolvimento local (IRVING e AZEVEDO, 2002).

Os impactos ambientais decorrentes desses usos podem ser observados por meio do aumento da geração de resíduos, pelos desmatamentos, construções em locais inadequados ou mesmo de risco e da grande aglomeração de pessoas em diversas áreas naturais e urbanizadas, sem planejamento turístico-ambiental e infraestrutura pertinente (HOEFFEL, 2011).

Para Schnaiberg e Gould (2000), que analisaram modelos econômicos sustentáveis, a atividade turística é considerada uma alternativa, no entanto, há a tendência de destruição do próprio setor quando existe uma expansão sem um planejamento 
Percepção do visitante sobre a relação entre turismo e meio ambiente no município de Campos do Jordão (SP)

adequado, isso pode ser notado em algumas localidades receptoras pela sobrecarga das infraestruturas locais, bem como diversos impactos sociais e culturais.

Para a evolução da atividade turística é essencial que exista uma gestão equilibrada do ambiente, seu elemento básico. A partir da década de 1950, o turismo passou a ter um crescimento acelerado resultando na degradação ambiental que atingiu vários pólos receptores. A principal consequência desse avanço é observado, notadamente, nos espaços naturais, e muitos países já demonstram sua preocupação sobre o assunto, o que incentiva a tomada de decisões ambientalmente mais amigáveis que favoreçam a proteção ambiental (RUSCHMANN, 1997).

Analisar a gestão da visitação em unidades de conservação é importante por muitas razões, principalmente pela relevância que as mesmas têm no Brasil para proteção da biodiversidade. Compreender os aspectos sociais, culturais, econômicos e ambientais envolvidos no ato da visitação pública em UCs é essencial para melhorar sua manutenção e continuidade como área de preservação.

A problemática ambiental tem avançado nas últimas décadas e está presente nas discussões da sociedade, instigando muitos estudos no intuito de avaliar os efeitos das ações humanas sobre o ambiente natural e discutir a relação atual entre o homem e a natureza (GRIFFITHS; HUGHES, 2001).

Considerando mudanças do século XX, McNeill (2001) destaca a intensidade das transformações, para a centralidade das ações humanas e as conseqüências inesperadas devido à diversidade de preferências e padrões sociais, políticos, econômicos e intelectuais. Nota-se que ao reconhecermos a imparcialidade das ações e percepções humanas, a questão ambiental é discutida e analisada de forma que não haja neutralidade, mas sim uma variação de interesses dos envolvidos e a ocorrência de conflitos entre valores, atitudes, percepções, conceitos e estratégias sociais (TUAN, 1980; MACHADO, 1996).

Para Redclift (1995), as chamadas avaliações ambientais são guiadas por intuitos sociais e utilizadas para se alcançar metas sociais específicas. Assim, quando o uso de alguns recursos naturais é discutido, estamos tratando também dos seus papéis dentro de um contexto social divergente, muitas vezes influenciado por uma concepção econômica, política, sócio-cultural ou ambiental dominante.

Woodgate e Redclift (1998) destacam a distinção entre diferentes indivíduos e instituições na visão sobre os sistemas ecológicos, pois são criações pessoais impregnadas pelas relações sociais materiais e simbólicas específicas.

Considerando também as relações entre o observador e o ambiente, Abram (1997) e Ferreira e Coutinho (2000) apontam que a percepção ambiental é afetada por fatores como a educação e a cultura, além de fatores sensitivos e afetivos. Ou seja, o indivíduo possui uma interpretação própria de acordo com suas experiências prévias, expectativas e ansiedades. Peterson (1999) complementa a idéia de que a forma como o ser humano compreende e identifica o valor da natureza está ligada ao contexto cultural, ao momento histórico vigente. 
Nesse sentido, Milton $(1996,2002)$ usa a antropologia para falar sobre o a sociedade e o ambiente, e acredita que as diversas culturas desenvolverão percepções distintas sobre a natureza, algo que também pode ser observado mesmo em culturas aparentemente homogêneas, tal a urbano-industrial de consumo.

Observando a inserção do turismo na questão ambiental, podemos nos apoiar em alguns autores, como Krippendorf (2000) que destaca a importância do turismo para gerar empregos e receitas, mas também uma preocupação por não haver debates e discussões que considerem que boa parte do desenvolvimento econômico trazido é formada de empregos afetados pela sazonalidade e baixos salários.

Nota-se que, ainda assim, o fator econômico é o que mais tem influenciado a exploração de recursos pelas atividades turísticas, negligenciando o comprometimento de outros fatores relacionados ao desenvolvimento das localidades receptoras.

Complementando o autor citado acima, Tuan (1980) afirma que apesar do turismo ser importante para a sociedade ao fomentar a economia, o mesmo não garante que exista harmonia na relação entre homem e natureza. Esta condição indica quão fundamental é a educação ambiental e o planejamento para envolver a todos e orientar a percepção para um turismo menos nocivo ao ambiente, ou seja, mais sustentável.

Para Cabral e Souza (2002), os conflitos gerados pela divergência de interesses podem não ser simples de se resolver e até mesmo implicar uma gestão ambiental complexa e não muito pacífica, pois se constrói o desafio de conciliar os propósitos e percepções para desenvolver o processo decisório tanto no âmbito público como no privado.

Ostrom (1990) também colabora no sentido de entender as razões que fazem com que alguns processos de gestão sejam bem desenvolvidos em alguns espaços e em outros não, pois, as ferramentas intelectuais necessárias ou os modelos para entender os problemas associados com o gerenciamento de recursos naturais são insuficientes e pouco efetivos para conciliação de interesses sobre os recursos naturais.

\section{Campos do Jordão (SP): uma aproximação histórico-geográfica}

A história do município de Campos do Jordão teve início em 1874 e passou por fases de ocupação e vocação diferentes até chegar a sua condição atual, com estruturas e atividades voltadas para o turismo que consolidaram a sua feição sócioeconômica baseada também na indústria de confecção de malhas e de chocolate, no artesanato e na exploração de água mineral (SEIBERT et al.,1975).

Segundo a Prefeitura de Campos do Jordão (2011), a maior fonte de renda é o turismo, sendo o grande responsável pelo desenvolvimento do município em outros setores.

Os visitantes são agentes transformadores dessa realidade, tornando a cidade 
Percepção do visitante sobre a relação entre turismo e meio ambiente no município de Campos do Jordão (SP)

da Serra da Mantiqueira, em alguns momentos de maior afluxo de turistas, numa vila de características tipicamente europeias. Com diversos significados socialmente construídos que estão na formação do imaginário coletivo em Campos do Jordão, há uma intenção definida de organizar o núcleo urbano, caracterizando-o como um espaço europeu que assim aparece na mídia, como já apareceu em outras épocas como a conhecida "Suíça" brasileira.

Em Campos do Jordão os turistas se sentem atraídos pelo que Ihes parece diferente e interessante, pelo que não vivenciam no cotidiano. Trata-se de um espaço de lazer, de distanciamento de hábitos e rotina, ou seja, daquilo vivido diariamente, como poluição, violência, barulho, trabalho desgastante e estresse.

De acordo com Ab'Sáber (2003), a topografia da região é montanhosa e acidentada, classificada como "Mares de Morros Florestados" ou "Planalto Atlântico" resultando em diversos recursos paisagísticos naturais que representam atrativos importantes para o turismo e prática de esportes de aventura.

A vegetação da região estudada tem predomínio originalmente da Mata Subtropical Perenifólia (EITEN,1983), ou Estacional Semidecidual, contando com fragmentos de araucária, Araucaria angustifólia e Araucaria podocarpus, muito prestigiada e importante na paisagem de Campos do Jordão (Figura 1) e especialmente do Parque Estadual de Campos do Jordão (VELOSO, 1991).

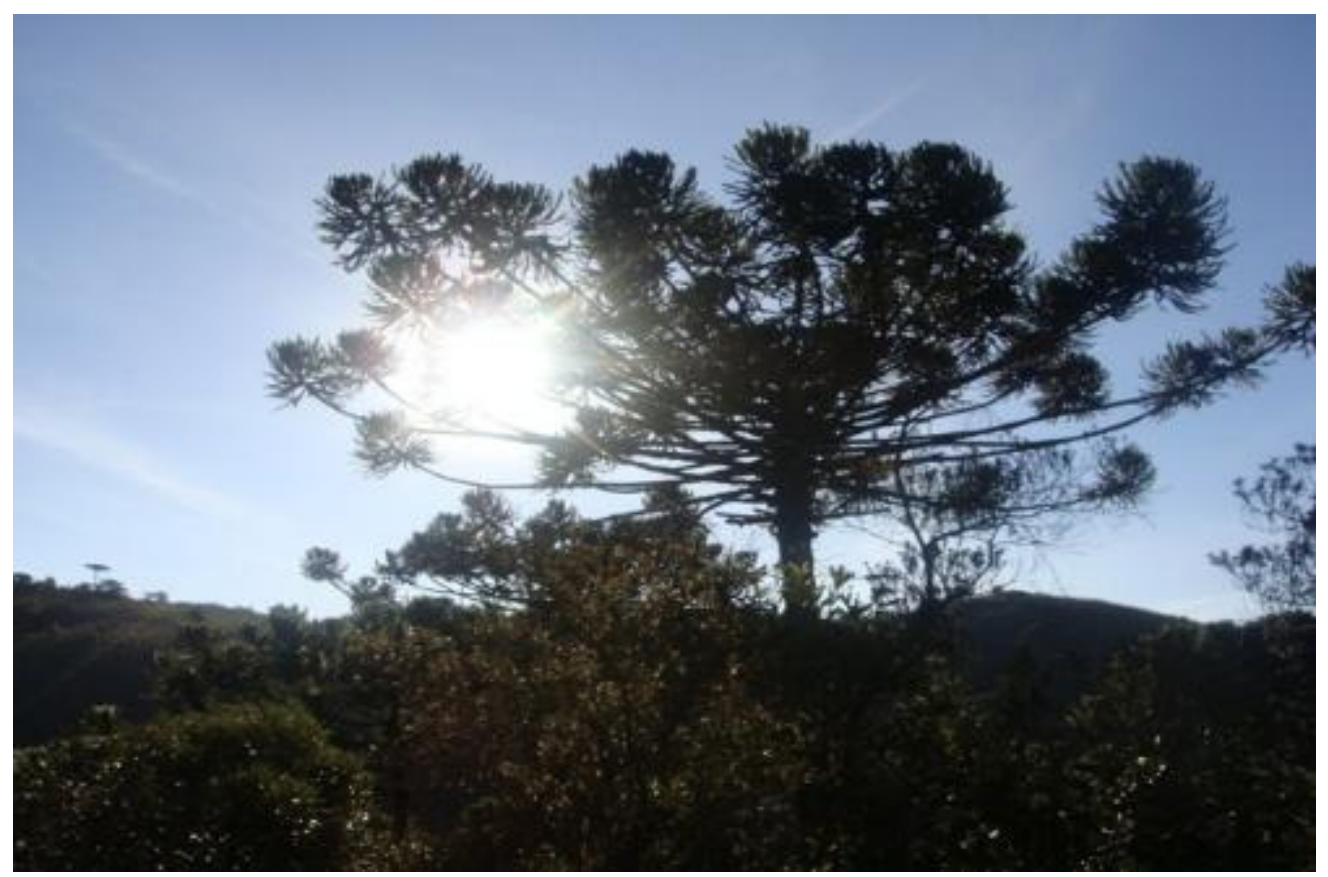

Figura 1: Paisagem de Campos do Jordão, SP. Foto: Sara Hirata (2011) Figure 1: Landscape of Campos do Jordão, Brazil. Photo: Sara Hirata (2011) 
Os aspectos climáticos da região relacionam-se à topografia, sendo que Andrade (1997) enuncia o clima como tropical de altitude, com ventos e precipitações brandas, elucidando o papel da geomorfologia das linhas mestras da Serra da Mantiqueira.

A amplitude térmica diária deste tipo de clima - tropical de altitude - é um dos maiores atrativos para o desenvolvimento do turismo, pois mesmo no verão as temperaturas são amenas, variando bastante durante o dia, chegando a mais de $30^{\circ} \mathrm{C}$, porém as noites são predominantemente frescas, ficando em torno dos $15^{\circ} \mathrm{C}$ (SIRGADO, 2001; AB'SÁBER, 2003).

O mês de julho é o mais procurado pelos turistas, configurando-se a alta estação quando o inverno está no auge, há pouca chuva e as temperaturas estão mais baixas, ocorrendo atividades de entretenimento com várias opções na região, quando Campos do Jordão e outros municípios vizinhos como São Bento do Sapucaí e Santo Antonio do Pinhal realizam festivais gastronômicos, de música, feiras e exposições de artesanato e cultura local (GRECCO, 2006).

\section{Parque Estadual de Campos do Jordão}

\section{Gestão de Unidades de Conservação: Parques Estaduais}

Em 2000 foi criado o Sistema Nacional de Unidades de Conservação (SNUC) por meio da lei № 9.985 de 18 de julho de 2000 que fala sobre a criação e manejo das Unidades de Conservação (UC) federais, estaduais e municipais, ação fundamental para um redirecionamento da gestão de áreas naturais no Brasil. O SNUC divide as áreas entre Unidades de Proteção Integral e Unidades de Uso Sustentável (BRASIL, 2000).

Os Parques Estaduais são semelhantes aos Parques Nacionais e estão entre as UC de Proteção Integral, caracterizadas pela destinação à proteção de áreas representativas de ecossistemas, "dotadas de atributos naturais ou paisagísticos notáveis", sítios geológicos de grande interesse científico, educacional, recreativo ou turístico, com a finalidade de resguardar atributos excepcionais da natureza, conciliando a proteção com o uso para fins científicos, educacionais e recreativos (BRASIL, 2000).

Nota-se que a legislação e as ações têm sido importantes para a preservação da natureza, no entanto, para Medeiros, Irving e Garay (2006), ainda que tenhamos uma evolução observada nas políticas públicas brasileiras de proteção do ambiente natural, expandindo as áreas protegidas, existem muitos fatores que interferem no seu efetivo funcionamento. Esses autores enfatizam a inexistência de uma estratégia clara de integração das unidades de conservação à dinâmica local e às questões globais, motivando diversos conflitos, decorrentes, no geral, da criação e implementação, pelo Estado, de áreas protegidas de forma autoritária e pouco participativa, desconsiderando a comunidade local. 
Percepção do visitante sobre a relação entre turismo e meio ambiente no município de Campos do Jordão (SP)

De fato, os conflitos também acontecem devido ao uso do espaço geográfico e da apropriação da terra por formas de utilização que não raramente são divergentes dos objetivos do manejo da unidade de conservação. Ferreira (1996) observa a situação de forma crítica, destacando a problemática causada pelo processo de seleção, implantação e gestão de áreas protegidas, por serem baseados em critérios ecológicos e econômicos, não se preocupando necessariamente com o sucesso dos resultados da conservação. Isso se deve ao fato do meio ambiente ser considerado como um bem público e de interesse universal, justificando-se, dessa forma, as tomadas de decisão por esferas denominadas competentes para esse fim.

Os impactos causados pela visitação em unidades de conservação devem ser compreendidos e avaliados quanto aos benefícios e aos efeitos indesejáveis que podem ter. Para Ruschmann (1997), os impactos do turismo são caracterizados entre positivos e negativos quanto a fatores sociais, culturais, econômicos e ambientais, interferindo na construção do espaço.

Segundo Ruschmann (1997, p.34), "os impactos do turismo referem-se à gama de modificações ou à sequência de eventos provocados pelo processo de desenvolvimento turístico nas localidades receptoras". Para a mesma autora existem variáveis do turismo desenvolvido junto ao meio ambiente que têm efeitos de natureza, intensidade, direções e magnitude distintos que resultam em interações muitas vezes irreversíveis.

\section{O Parque}

Os aspectos físicos, climáticos e históricos do Parque Estadual de Campos do Jordão (PECJ) explicam a sua significância no panorama estadual, localizado a cerca de 180 quilômetros de distância da capital paulista, na porção leste-nordeste do Estado de São Paulo, nas encostas da Serra da Mantiqueira.

O PECJ está localizado no município de Campos do Jordão, ocupando um terço de seu território com uma área de 8.341 hectares, tendo sido criado em 27 de março de 1941 pelo Dec. Lei 11.908, (Figura 2) é o mais antigo de São Paulo (FUNDAÇÃO FLORESTAL, 2011).

Situado num dos centros turísticos mais importantes do Brasil, o PECJ recebia, em 1997, mais de 2.000 visitantes por dia durante a alta temporada, entre junho e juIho (DECANINI, 1997). De acordo com funcionários da atual gestão do PECJ (COMUNICAÇÃO ORAL, 2011) o número de turistas por dia em alta temporada sofreu uma redução, alcançando em média 60.000 visitantes por ano, embora ainda seja um dos Parques estaduais mais procurados de São Paulo.

Os principais atrativos do PECJ são, conforme a Fundação Florestal (2011), as trilhas chamadas Monteiro Lobato, Quatro Pontes, Cachoeira, Rio Sapucaí, Celestina e Campos, contemplando a demanda de um público variado entre crianças, jovens, adultos e idosos. Além das trilhas, existem serviços dentro do parque como lanchone- 
te que serve pequenas refeições, loja de artesanatos, chocolates produzidos no município entre outras coisas.

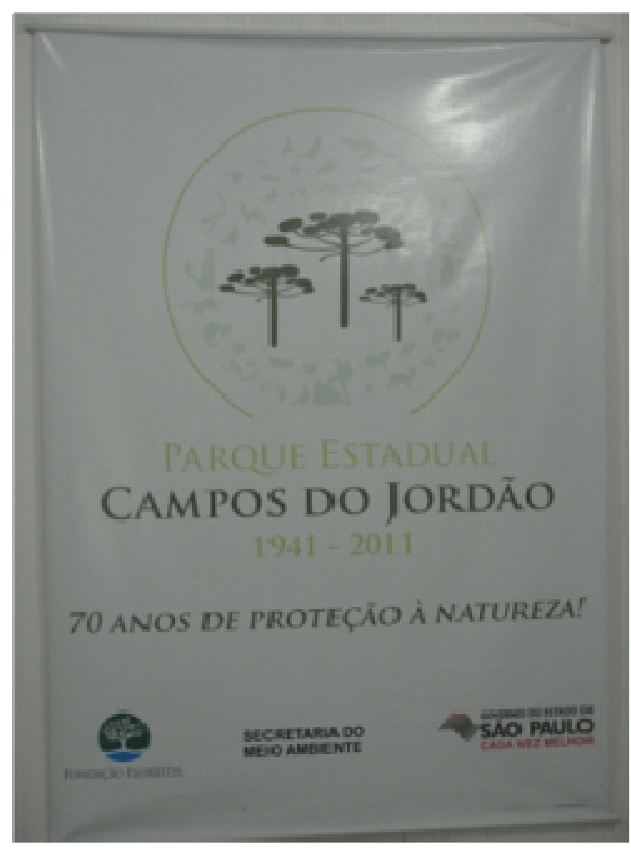

Figura 2: Pôster de comemoração aos 70 anos de existência do PECJ. Foto: Sara Hirata (2011). Figure 2: Poster commemorating the 70th anniversary of PECJ. Photo: Sara Hirata (2011).

\section{Procedimentos metodológicos}

\section{Coleta de dados}

Gestão Ambiental é um dos cursos da Universidade de São Paulo (USP) no campus de Piracicaba, a Escola Superior de Agricultura "Luiz de Queiroz". A graduação ocorre de forma multidisciplinar envolvendo os estudantes em diferentes temáticas que vão desde a Botânica Sistemática até as disciplinas sobre Administração Financeira, Direito Ambiental e também sobre Turismo.

Nesse contexto, os alunos do sétimo semestre de Gestão Ambiental, matriculados na disciplina Gestão Turística de Ambientes Naturais (GTAN), têm a oportunidade de aprofundamento com o tema.

Entre os exercícios da disciplina, desenvolve-se uma prática orientada em Campos do Jordão, município do estado de São Paulo que recebe uma atividade turística intensa, especialmente nos meses de inverno (junho, julho e agosto), considerada a estação da alta temporada de visitação. O estudo do meio acontece, anualmente, nesse período, objetivando o levantamento e análise da movimentação turística local.

Campos do Jordão é um pólo receptor de turismo já consolidado, tendo certas características naturais que tornam a área vulnerável, apresentando diversas fragilida- 
Percepção do visitante sobre a relação entre turismo e meio ambiente no município de Campos do Jordão (SP)

des ambientais com terrenos íngremes e sujeitos a escorregamentos, sofrendo os impactos da ocupação desordenada e efeitos da visitação. O Parque Estadual Campos do Jordão (PECJ) é uma unidade de conservação neste contexto.

Nesse cenário apresentado, os alunos de GTAN presenciam situações cujo objetivo é a reflexão sobre as questões ambientais e sua relação com o turismo desta localidade. Os discentes têm a oportunidade de conhecer aspectos das áreas rural e urbana, observando os pontos de maior afluxo de turistas como as Vilas Capivari e Abernéssia, onde há grande concentração de meios de hospedagem e de restauração, bem como comércio de artesanato, malhas e produtos alimentícios produzidos localmente. Atrativos culturais e históricos também são conhecidos como o Palácio Boa Vista funcionando como museu de arte contemporânea e, ao mesmo tempo, como residência de inverno do Governador paulista.

O momento crucial do estudo é a visita ao PECJ (Figuras 3 e 4), área protegida de grande valor ambiental, onde há possibilidade de observação dos aspectos paisagísticos, flora, fauna, infraestrutura receptiva e aspectos de gestão.
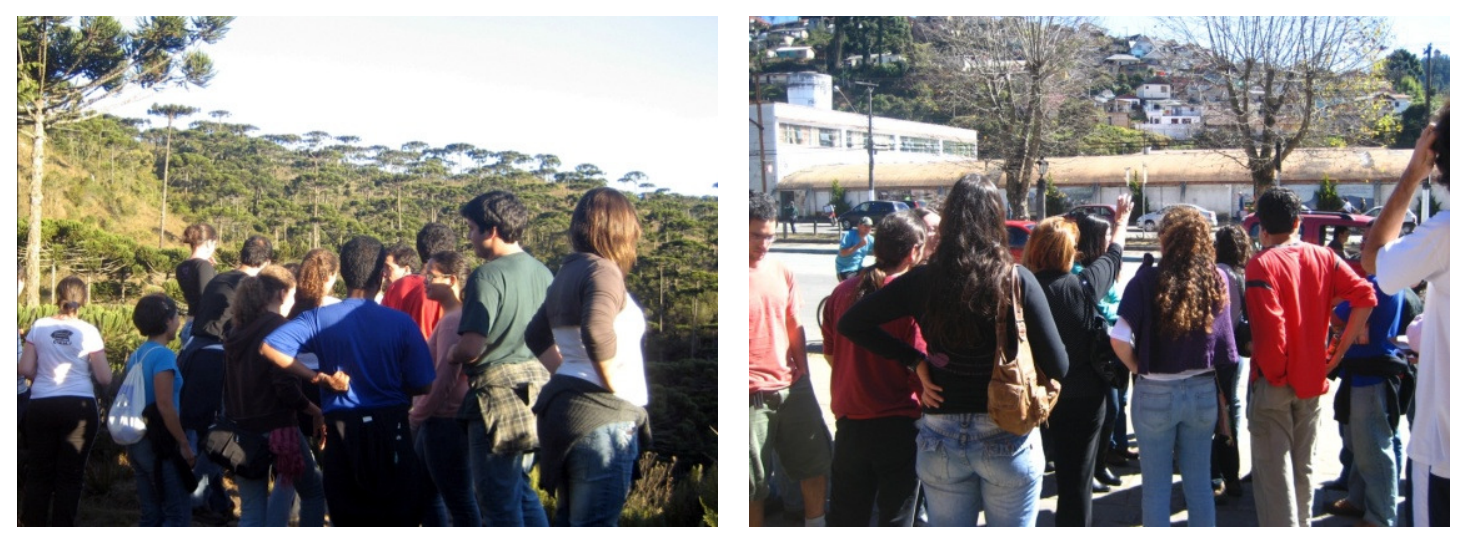

Figuras 3 e 4: Discentes do curso de Gestão Ambiental da ESALQ/USP durante atividades da prática orientada em Campos do Jordão,SP. Fotos: Sara Hirata (2010).

Figures 3 and 4: Students from the Environmental Management ESALQ / USP's activities during guided practice in Campos do Jordão, Brazil. Photos: Sara Hirata (2010)

O estudo conta ainda com palestras realizadas graças ao apoio das Secretarias de Meio Ambiente e de Turismo, quando profissionais da administração municipal expõem a real situação da estância climática de Campos do Jordão, dissertando sobre as potencialidades e problemas encontrados.

Como atividade final da prática orientada há a realização de entrevistas semiestruturadas por grupos de alunos que se dividem na abordagem de visitantes, comerciantes, hoteleiros e moradores locais, com o propósito de colher informações gerais sobre o turismo. 
As entrevistas geram em média cem formulários com informações dos segmentos descritos, dentre elas, dez a vinte são de visitantes abordados nas Vilas Capivari e Abernéssia onde há, notadamente, maior concentração de visitantes, atores sociais escolhidos para análise neste artigo. A partir desta dinâmica de visita dos alunos de 2007 a 2011 a Campos do Jordão, foram geradas as informações que servem para reflexão e discussão sobre a realidade local.

Gil (2000) define a entrevista como uma técnica de apresentação entre o pesquisador e o pesquisado no intuito de formular perguntas que levantem dados de interesse da investigação. Para coletar dados, a técnica é considerada relevante devido à flexibilidade de estruturação, pertinente na obtenção de informações referentes ao que o entrevistado sabe, crê, espera, sente ou deseja, pretende fazer, faz ou fez.

Assim, as questões que guiaram a abordagem sobre os turistas foram construídas para levantar o perfil do visitante, como gênero, faixa etária, escolaridade e local de origem. Outras questões também foram feitas sobre o meio de transporte usado para ir até Campos do Jordão, a frequência de visitação anual, os principais atrativos sob a visão dele e a percepção sobre os impactos socioambientais do turismo na região.

Dessa maneira, buscou-se compreender os atributos de experiência e preferência pessoal do visitante. A percepção foi avaliada por meio do levantamento da opinião dos visitantes sobre as condições do parque e os efeitos que acreditam causar sobre a unidade de conservação.

\section{Resultados e discussão}

Por meio das entrevistas realizadas entre 2007 e 2011, foi possível organizar as informações concedidas por 72 indivíduos permitindo uma análise focada na temática ambiental pela percepção do turista.

Das questões aplicadas para compreensão a respeito do perfil dos visitantes, tivemos que o público feminino ficou um pouco acima da população masculina com $53,85 \%$, sendo que do total entrevistado $40,38 \%$ disse ter entre 26 e 40 anos.

Uma grande parte dos entrevistados é proveniente da capital paulista, ou seja, 43,90\% são de São Paulo e percentagens menores pulverizadas entre outras cidades paulistas e algumas de Minas Gerais e do Rio de Janeiro.

Os turistas também apontaram que o transporte mais utilizado para ir até Campos do Jordão é o automóvel, com $71,15 \%$ das respostas, sendo que $64,71 \%$ já conheciam o município e estavam voltando, confirmando a frequência de visitação anual de uma parcela dos visitantes.

$\mathrm{Na}$ etapa seguinte, com questões voltadas à percepção ambiental dos entrevistados sobre os impactos do turismo, tivemos os respectivos percentuais de respostas (Figura 5): 
Percepção do visitante sobre a relação entre turismo e meio ambiente no município de Campos do Jordão (SP)

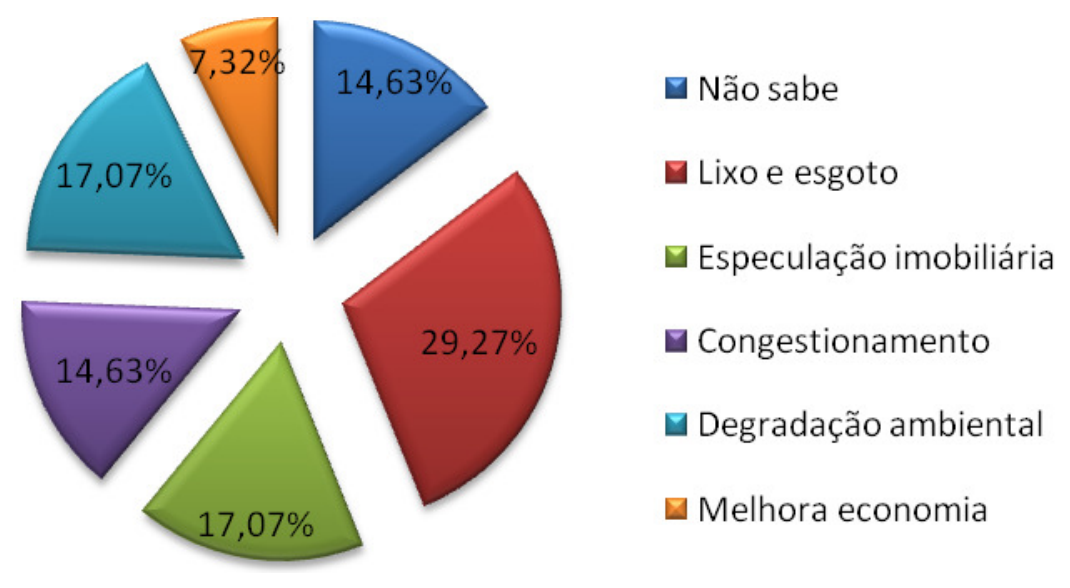

Figura 5: Percepção sobre os impactos socioambientais causados pelo turismo.

Figure 5: Perception about the environmental impacts caused by tourism.

Interrogados sobre as principais motivações para visitar Campos do Jordão, as respostas dos turistas são tratadas no gráfico abaixo. (Figura 6).

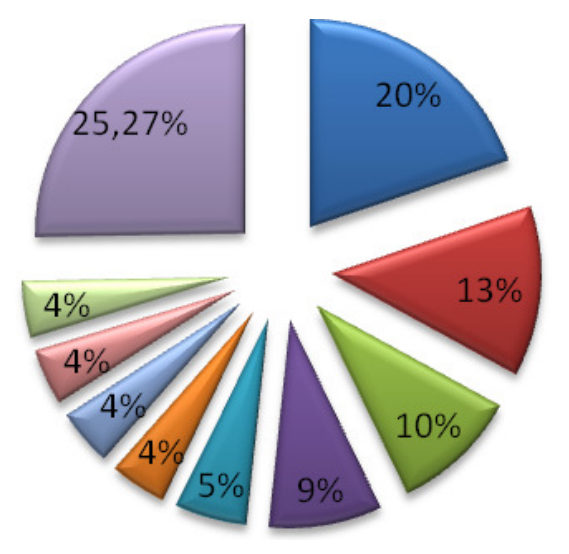

\author{
Clima/frio \\ - Comida/chocolate \\ $\square$ Centro/capivari \\ Beleza/paisagem \\ $\square$ Trenzinho \\ $\square$ Palácio \\ $\square$ Parque Estadual \\ $\square$ Teleférico \\ $\triangle$ Baden \& Baden \\ $\square$ Outros
}

Figura 6: Percepção sobre os principais atrativos de Campos do Jordão (SP).

Figure 6: Perception of the main attractions in Campos do Jordao (SP, Brazil).

Merece destaque uma informação obtida nas entrevistas que diz respeito à ausência de indicação do PECJ como um dos principais atrativos do turismo jordanense, embora $36,54 \%$ dos entrevistados afirmaram conhecê-lo. Essa informação pode indicar que esta unidade de conservação é relevante nos panoramas do município e região, no entanto seu potencial como atrativo turístico não é plenamente desenvolvido, 
há outros locais com maior visibilidade.

Constatou-se que os visitantes, em sua maioria, têm o ensino superior completo, se deslocam de veículo próprio, indicando que aqueles que procuram a estância pertencem a uma classe social razoavelmente abastada e com bom nível de instrução.

Os indivíduos entrevistados que comentaram sua relação com o local, identificaram características atraentes como o frio e o aspecto de cidade do interior, como tranquilidade, simplicidade e presença de natureza preservada. Como tratado por Urry (2002), essa relação denota a atração pela área devido à desilusão com elementos modernos e urbanos em seus locais de origem. É viável supor que tais frequentadores vivenciam em seus cotidianos um ambiente cosmopolita, espaço com poucos elementos naturais e paisagísticos, falta de segurança e tranquilidade, fatores que passaram a procurar em outros lugares.

Das informações sobre a opinião dos entrevistados envolvendo a temática ambiental e o PECJ, observou-se que uma parcela razoável pouco soube opinar sobre os impactos do turismo junto aos recursos naturais do município, embora reconheçam como efeitos indesejáveis a geração de lixo e esgoto.

Aspectos importantes como a construção de complexos hoteleiros e condomínios de segunda residência, abundantes e em crescimento no município, muitas vezes, causadores de inúmeros rearranjos socioespaciais e ambientais desastrosos não são notados pelos entrevistados como algo negativo. A desigualdade social evidente também não é elemento percebido, denotando superficialidade de interação com a realidade local, ou seja, há indício de que a estadia dos visitantes é estreitamente relacionada ao espaço construído para recebê-los, concentrados nas vilas turísticas intencionalmente projetadas para o perfil turístico apresentado, não havendo relação com o espaço do município como um todo, incluindo suas fragilidades ambientais e de inclusão social dos moradores locais.

Notadamente um fator relevante para Campos do Jordão, concluiu-se que um dos principais atrativos citados é o clima tropical de altitude, apresentando grande amplitude térmica durante o dia e esfriando rapidamente quando a noite chega, oferecendo uma sensação diferente do clima tropical que abrange a maior parte do território brasileiro.

Apontam os resultados, que uma grande parcela dos entrevistados conhece o Parque Estadual de Campos do Jordão, no entanto seu potencial de visitação não é explorado a ponto de ser indicado como um dos principais atrativos. O PECJ é o parque mais visitado do interior paulista, tratando-se de uma unidade de conservação com muita atratividade em relação às demais na mesma categoria de UC, porém inferior no cenário de mais de um milhão de visitantes que Campos do Jordão recebe na alta temporada de visitação (ARAUJO,2008).

Barbieri (1997) em seu estudo sobre o PECJ destaca que há divergências en- 
Percepção do visitante sobre a relação entre turismo e meio ambiente no município de Campos do Jordão (SP)

tre as razões que levam os turistas até lá e as atividades ali desenvolvidas, apontando desconhecimento sobre os objetivos de um parque estadual. Essa constatação pode indicar que muitos visitantes procuram o PECJ apenas por acreditar que seja um "ponto turístico", sem muita consciência de sua condição de Parque Estadual conforme descrito pelo SNUC.

O planejamento e a sensibilização são instrumentos que permitem uma aproximação do visitante e podem proporcionar uma sensação de pertencimento e valorização destes ambientes como o do PECJ.

\section{Considerações finais}

Considerando as informações obtidas com os visitantes entrevistados dentre outras referências sobre o lugar, pode-se dizer que Campos do Jordão recebe turistas com os mais variados perfis socioeconômicos. A maioria objetiva ter uma vivência relacionada aos aspectos urbanos concentrados na Vila Capivari onde há uma reprodução daquilo encontrado nos bairros mais elitizados da capital, São Paulo, ou seja, bons hotéis e restaurantes luxuosos, lojas de marca, enfim, ambiente sofisticado muito valorizado socialmente.

Há também visitantes que são altamente motivados pela ocorrência de temperaturas mais baixas e raras no território paulista, mas sentem-se fortemente atraídos pelas belezas cênicas da região, ansiosos pelo contato com a natureza e provavelmente são estes que mais visitam o Parque Estadual de Campos do Jordão.

Campos do Jordão tem selado à sua história o turismo como atividade que dinamiza sua economia e consequentemente os demais setores da sociedade. Cabe ao município, na forma de governantes e sociedade organizada, como em outros que também são destinos turísticos no Brasil, o planejamento que envolva não apenas as relações econômicas da atividade, favorecendo estruturas que abriguem os turistas, incorporando os aspectos sociais e ambientais na política de construção de um turismo mais suave e inclusivo. $\mathrm{O}$ uso de instrumentos que direcionem o envolvimento entre os visitantes e o município como um todo, agregando outras áreas da cidade e do meio rural, incentivando a participação e engajamento da população local pode ser um caminho mais real e apropriado para o desenvolvimento sustentável local.

\section{Referências Bibliográficas}

ARAÚJO, R.S.P. A Viabilização de Parques com o Apoio do Turismo - O Caso do Parque Estadual de Campos do Jordão. 2008. 123 f. Dissertação (mestrado) - Faculdade de Filosofia, Letras e Ciências Humanas, Universidade de São Paulo, São Paulo, 2008.

AB'SÁBER, A.N. Os domínios de natureza do Brasil: potencialidades paisagísticas. São Paulo: Ateliê Editorial, 2003. 
ABRAM, D. The spell of the sensuous. New York: Vintage Books, 1997. 352 p. ANDRADE, J. V. Turismo: fundamentos e dimensões. São Paulo: Ática, 1997.

BARBIERI, M. G. Análise de Programas de Uso Público em Unidades de Conservação do Estado de São Paulo - Revisão e Estudo de Caso para o Parque Estadual de Campos do Jordão. Dissertação (Mestrado). PROCAM/USP, São Paulo: 1997. 238p.

BRASIL. Ministério do Meio Ambiente. Lei n 9.985, de 18 de julho de 2000: Sistema Nacional de Unidades de Conservação da Natureza. Brasília: MMA; IBAMA; Funatura; 2000, 32p.

CABRAL, N. R. A. J.; SOUZA, M. P. Área de Proteção Ambiental: planejamento e gestão de paisagens protegidas.São Carlos: RiMa, 2002.154 p.

CUNHA, A. S da; LEITE, E. B. Percepção Ambiental: Implicações para a Educação Ambiental. Sinapse Ambiental. 2009 pp. 66-79.

CZAPSKI, S. A implantação da educação ambiental no Brasil. Brasília: MEC, 1998. $166 \mathrm{p}$.

DECANINI, M. M. S. The Introduction of GIS Technology in the State Parks -State of São Paulo: Constraints and Opportunities, Edinburgh: Edinburgh University, 1997.

DíAZ, A. Educação Ambiental como Projeto. 2.ed. Porto Alegre:. Artmed, 2002.

EITEN, G. Classificação da Vegetação do Brasil. Brasília: CNPq/Coordenação Editorial, 1983.

FERREIRA, L. C. Os ambientalistas, os direitos sociais e o universo da Cidadania. In: FERREIRA, L.C.; VIOLA, E. (orgs). Incertezas de sustentabilidade na globalização. Campinas: Unicamp, 1996.

FERREIRA, L. F.; COUTINHO, M. C. B. Educação ambiental em estudos do meio: a experiência do Bioma Educação Ambiental. In: SERRANO, C. A educação pelas pedras. São Paulo: Chronos, 2000. pp. 171-188.

GARNICA, A. V. C. Algumas Notas sobre Pesquisa Qualitativa e Fenomenologia. Interface - Comunicação, Saúde e Educação, São Paulo, v.1, n.1,1997.

GIL, A. C. Técnicas de Pesquisa em economia e elaboração de monografias. $-3^{a}$ ed. São Paulo : Atlas, 2000.

GRECCO, A. P. As atividades ecoturísticas e de aventura no contexto paisagístico de São Bento do Sapucaí - SP. Dissertação (mestrado), Universidade Estadual Paulista Júlio de Mesquita Filho - Rio Claro : [s.n.], 2006 - 152 f. : il., tabs., fots., mapas

GRIFFITHS, T.; ROBIN, L. Ecology and Empire. Pietermaritzburg: Keele University Press, 2001. $248 \mathrm{p}$. 
Percepção do visitante sobre a relação entre turismo e meio ambiente no município de Campos do Jordão (SP)

HUGHES, J. D. An Environmental History of the World. London: Routledge, 2001. $264 \mathrm{p}$.

HOEFFEL, J.L.; FADINI, A.A.B.; MACHADO, M.K.; REIS, J.C. Trajetórias do Jaguary: - unidades de conservação, percepção ambiental e turismo: um estudo na APA do Sistema Cantareira. São Paulo. Ambient. soc., Campinas, v. 11, n. 1, June 2008.

IRVING, M. A. Uma reflexão sobre conservação ambiental e qualidade de vida no Brasil: Estudo de Caso. Revista Série Documenta, v. 7, n. 10, p. 59-82, 2001.

IRVING, M. A.; AZEVEDO, J.; Turismo: o desafio da sustentabilidade. São Paulo: Futura, 2002.

JACOBI, P. Educação Ambiental e Cidadania. In: CASCINO, F.; JACOBI, P.; OLIVEIRA, J. F. (Orgs.). Educação, meio ambiente e cidadania: Reflexões e experiências. São Paulo: SMA/CEAM, 1998. pp. 11-14.

KRIPPENDORF, J. Sociologia do turismo: para uma nova compreensão do lazer e das viagens. São Paulo: Aleph, 2000. 186 p.

LEITE, E.B. Diagnóstico socio ambiental participativo: uma proposta para subsidiar os estudos em percepção ambiental em comunidades. Mimeo. 2009

MACHADO, L. M. C. P. Paisagem valorizada: A Serra do Mar como espaço e lugar. In: DEL RIO, V.; OLIVEIRA, L. Percepção ambiental: A experiência brasileira. São Paulo: Nobel, 1996. pp. 97-119.

MARQUES DE SÁ, A. L. R. S. São Bento do Sapucaí (SP): A formação de uma localidade turística. São Paulo, 2002. Dissertação (Mestrado). Universidade de São Paulo. Escola de Comunicação e Artes.

McNEILL, J. R. Something new under the sun: an environmental history of the twentieth-century world. New York: Norton, 2001. $421 \mathrm{p}$.

MEDEIROS, R.; IRVING, M.; GARAY, I. Áreas protegidas no Brasil: Interpretando o contexto histórico para pensar a inclusão social. In: IRVING, M. (Org.) Áreas Protegidas e Inclusão Social. Rio de Janeiro: Aquarius, 2006. pp. 13-40.

MILTON, K. Environmentalism and cultural theory. London:Routledge, 1996. 266 p.

MILTON, K. Loving nature. London: Routledge, 2002. 182 p.

OSTROM, E. Governing the commons: the evolution of institutions for collective action. Cambridge: Cambridge University Press, 1990. 296 p.

PACHECO, É.; SILVA, H.P. Compromissos Epistemológicos do Conceito de Percepção Ambiental. Rio de Janeiro: Departamento de Antropologia, Museu Nacional e Programa EICOS/UFRJ, 2007.

PETERSON, A. Environmental ethics and the social construction of nature. Environmental Ethics, Denton, v. 21, n. 4, pp. 339-357, 1999. 
PREFEITURA MUNICIPAL DE CAMPOS DO JORDÃO. Disponível em: http:// www.camposdojordao.sp.gov.br/. Acesso em 10 mar 2011.

QUEIROZ, O.T.M.M. Impactos das atividades turísticas em área de reservatório: uma avaliação sócio-ambiental do uso e ocupação na área da represa do Lobo, município de Itirapina, SP. Tese (Doutorado). EESC. USP, 2000.

REDCLIFT, M. In our image: the environment and society as global discourse. Environment and history, Cambridge, v. 1, n. 1, pp. 111-123, 1995.

RUSCHMANN, D.M. Turismo e Planejamento Sustentável: A proteção do meio ambiente. 1997. Campinas, SP: Papirus 2006. 13 ed.

SCHNAIBERG, A.; GOULD, K. A. Environment and society. New York: Blackburn, 2000. 255 p.

SEIBERT, P., NEGREIROS, O.C., BUENO, R.A., EMMERICH, W., MOURA NETTO, B.V., MARCONDES, M.A.P., CESAR, S.F., GUILLAUMON, J.R., MONTAGNA, R.A.A. NOGUEIRA, J.C.B., GARRIDO, M.A.O., MELLO FILHO, L.E., EMMERICH, M., de MATTOS, J.R., OLIVEIRA, M.C. \& GODOI, A. Plano de Manejo do Parque Estadual de Campos do Jordão. Boletim Técnico do Instituto Florestal de São Paulo, 19: 1$153+$ Atlas, 1975 .

SIRGADO, J. R. Espaço turístico e desenvolvimento no Cone Leste Paulista, In: RODRIGUES, A. B. (org.) Turismo rural. São Paulo: Contexto, 2001.

TUAN, Yi-Fu. Topofilia: Um estudo da percepção e valores do meio ambiente. São Paulo: Difel, 1980. 288 p.

URRY, J. The tourist gaze. London: SAGE, 2002. 183 p.

VELOSO, H. P. et al. Classificação da vegetação brasileira, adaptada a um sistema universal. Rio de Janeiro: IBGE, Departamento de Recursos Naturais e Estudos Ambientais, 1991.

WHITEHEAD, Alfred North. 0 conceito de natureza. São Paulo: Martins Fontes, 1994.

WOODGATE, G.; REDCLIFT, M. From a 'sociology of nature' to environmental sociology: beyond social construction. Environmental Values, Cambridge, v. 7, n. 1, pp. 3-24, 1998.

\section{Agradecimentos}

Agradecemos a CAPES pelo apoio financeiro por meio da bolsa de mestrado concedida à mestranda, primeira autora do trabalho.

Agradecemos também aos discentes de Gestão Ambiental que participaram das entrevistas feitas com turistas em Campos do Jordão entre os anos de 2007 e 2011. 
Percepção do visitante sobre a relação entre turismo e meio ambiente no município de Campos do Jordão (SP)

Sara Ruiz Hirata: Escola Superior de Agricultura Luiz de Queiroz - USP, Piracicaba, SP, Brasil.

Email: sara.hirata@usp.br

Link para o currículo Lattes: http://lattes.cnpq.br/1784228089221983

Odaléia Telles Marcondes Machado Queiroz: Escola Superior de Agricultura Luiz de Queiroz - USP, Piracicaba, SP, Brasil.

Email: otmmquei@esalq.usp.br

Link para o currículo Lattes: http://lattes.cnpq.br/6995118783898309

Data de submissão: 27 de fevereiro de 2012

Data de recebimento de correções: 05 de maio de 2012

Data do aceite: 17 de agosto de 2012

Avaliado anonimamente 